Wayne State University

DigitalCommons@WayneState

Music Faculty Research Publications

Music

$10-1-2007$

\title{
Singing Down the Barriers: Encouraging Singers of All Racial Backgrounds to Perform Music by African American Composers
}

Caroline Helton

University of Michigan - Ann Arbor

Emery Stephens

Wayne State University, ej8431@wayne.edu

\section{Recommended Citation}

Helton, C. and Stephens, E. (2007), Singing down the barriers: Encouraging singers of all racial backgrounds to perform music by African American composers. New Directions for Teaching and Learning, 2007: 73-79. doi: 10.1002/tl.288

Available at: http://digitalcommons.wayne.edu/musicfrp/2

This Article is brought to you for free and open access by the Music at DigitalCommons@WayneState. It has been accepted for inclusion in Music Faculty Research Publications by an authorized administrator of DigitalCommons@WayneState. 
This chapter investigates the barriers faced by singers of all racial backgrounds when performing spirituals and African American art songs and suggests ways to eliminate those barriers.

\title{
Singing Down the Barriers: Encouraging Singers of All Racial Backgrounds to Perform Music by African American Composers
}

\author{
Caroline Helton, Emery Stephens
}

The idea for our project developed in a doctoral seminar taught by Caroline Helton, a white faculty member in voice at the University of Michigan. In a presentation on the performance practice of singing spirituals, Emery Stephens, an African American graduate student in the seminar, concluded by encouraging everyone in the room (all white with the exception of one Asian student) to program spirituals on their recitals. The halting reply was "We can't because we're not black," to which Emery replied, "Why not?" Thus began our journey toward investigating the barriers singers face when they attempt to perform spirituals and art songs by African American composers. However, finding out about the barriers is useless unless we can break them down and allow all students to benefit musically, artistically, and socially from the experience of singing this repertoire.

As we began to explore this subject, four questions emerged to guide our research:

- What are the barriers that singers from all racial backgrounds face when performing art songs and spirituals by African American composers?

- How do students and teachers confront their preconceptions when learning any piece of music (for example, a female student singing a song from

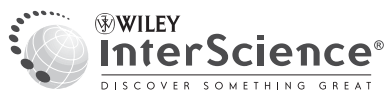

New Directions for Teaching And Learning, no. 111, Fall 2007 (c) Wiley Periodicals, Inc.

Published online in Wiley InterScience (www.interscience.wiley.com) • DOI: 10.1002/tl.288 
a man's perspective)? Specifically, how can that process be applied to learning spirituals and art songs by African Americans?

- How is a singer's outlook on racial dynamics affected by studying and performing these pieces?

- What do we need to do as educators to enable singers from all racial backgrounds to become more comfortable performing this repertoire?

Before we turn to these questions, we would like to define some of the musical terms we are using and give a brief historical overview of the issues that make performance of this repertoire a complicated matter.

The term art song refers to a composition for voice and piano in which the composer has chosen to set to music a preexisting text (poetry as opposed to lyrics), as Franz Schubert did with the Goethe poem "Erlkönig" and Aaron Copeland did with some of Emily Dickinson's works. The resulting composition involves a musical union in which piano and vocal lines support and complement one another in a way that elucidates the composer's conception of the poem. Unlike folk songs, which are anonymous and passed down through an oral tradition, art songs remain the domain of the "trained" composer, who is intending the pieces to be performed by classical musicians. However, this distinction is not always complete, because trained composers have often been drawn to set existing folk melodies to a similarly intentioned accompaniment. Even though these settings are of folk melodies, they more resemble art songs because they are written with the skills of the trained singer and pianist in mind. African American spirituals fall into this category of "folk song settings," as they are drawn from the largest body of folk songs in America, popular with white and black audiences alike for over a century, whether they are sung solo or in choral arrangements.

Our modern cultural quandary concerning performance practice stems from the complex history surrounding the provenance of spirituals. Early African American spirituals, once called "Negro spirituals" or "plantation slave songs," were inspired by African and Western European musical and religious traditions and were originally sung in "slave dialect." These songs were adopted and sung by slaves as work songs during their daily activities. These pieces are thus intimately connected to the history of slavery in the United States (Southern, 1971).

The nineteenth century also saw the meteoric rise in the popularity of minstrel shows, in which white performers blackened their faces and played stock characters modeled on slave stereotypes. Beginning in the 1840s and for several decades thereafter, minstrel shows were the most popular stage entertainment in America. Black performers were eventually allowed to take part in minstrel shows, also wearing black face makeup. Ironically, this was one of the first professional outlets for black singers, who were by and large prohibited from performing for a wider audience in any other genre (Hamm, 1979; Southern, 1971). 
The current sensitivity to race in the performance of art songs and spirituals by African American composers stems from our nation's history of slavery and oppression on the one hand and the legacy of minstrelsy and its stereotyping and mocking of African Americans on the other. Though these events are now far removed from our experience, their repercussions are still palpable in our cultural dynamics today. Time has not healed this wound but rather obscured the path to the cure. Since art songs and spirituals by African Americans connect directly to both of these historical phenomena, performing them could provide a means of exploring and defusing the racial sensitivity we feel today (Plant, 2005).

Our inquiry began as a discussion of the barriers experienced by singers of all races when approaching this repertoire. To find out more about how singers of today view this delicate topic, we developed an e-mail survey that we sent to five hundred singers in the professional world and at academic institutions. We received 218 responses, a response rate of 43 percent. The survey included questions on demographics (gender, age, ethnic background, religious affiliation), musical training, exposure to art songs and spirituals by African Americans, preferences of vocal performance style, and attitudes toward performance of this repertoire by singers of all racial backgrounds (focusing on perceptions of authenticity). Approximately one-quarter (23 percent) of the respondents were African American and three quarters (73 percent) Caucasian. Nearly three-quarters ( 72 percent) of the respondents have at least one degree in music, 50 percent identified themselves as voice teachers and professional singers, and 39 percent described themselves as voice students. Sixty-two percent said they had never received any instruction on singing African American art songs or spirituals in their private or institutional voice studio, but an overwhelming majority (87 percent) said they would like to perform this literature.

Our analysis of the responses to the question about challenges to performing this repertoire broke down into four categories. Roughly onequarter of responses expressed fears of inauthenticity or needing permission to perform the repertoire. Another quarter cited lack of availability or knowledge of where to find pieces. A slightly greater number of respondents felt that they lacked sufficient stylistic knowledge or guidance to interpret the repertoire correctly and respectfully, and a small number of singers cited ignorance (on the part of the general public or colleagues or their own musical shortcomings) as a barrier.

The survey also asked about the extent to which a performer's race contributes to the authenticity of his or her performance of this repertoire. Approximately 25 percent of the respondents felt that race greatly contributed to perceptions of authenticity, while 62 percent rated the contribution moderate, and 13 percent felt that the race of the performer did not play any role at all. When asked to explain their rating, responses indicating that race played a major role came from African Americans, who felt a strong 
sense of ownership of the repertoire, and non-African Americans, who assumed that they wouldn't be accepted by audiences:

I think that at this point race plays a major part in the authenticity of singing African American art songs, simply because many teachers of other races have not taken the time to know this material well enough to teach students how to approach them with understanding and appreciation for the history and culture behind them.

I think African Americans can sing these types of songs more authentically, and I feel like I don't have as much of a right to perform this type of music because I'm not black. But I think if more singers of all races were to sing this type of material, it would become more widely accepted.

The majority of respondents, however, felt that singers of all racial backgrounds must actively work to connect to the literature they sing. They said that it may be easier for some African American singers who have had certain experiences to connect to the repertoire, but that does not rule out the responsibility borne by any singer to create an authentic and committed performance; in other words, race alone does not bestow authenticity on the singer. Respondents observed, "It's not so much race as it is level of familiarity with the style" and "A good understanding of the history of African American art songs, the text of the song, and how to properly sing it is necessary, and these factors have nothing to do with race."

In fact, when asked how comfortable they would be if singers of all races performed this repertoire, virtually all of respondents (99 percent) reported a high or moderate level of comfort. In response to open-ended questions, two singers spoke eloquently of the possibility for cross-cultural communication:

As a fellow African American, it is my duty, and the duty of other African Americans, to continue performing the songs of our past to others. I believe that is very important to do; however, when people of other races sing these wonderful songs the message of continuing the story is extended to a greater family of people, beyond race.

I do not believe that music has a soul, but it does leave the imprints of peoples' spirits and communicates on a deeper level than our verbal language can ever begin to communicate.

It is this very idea that leads us to explore ways of helping artists from all backgrounds perform this music.

Our first step was to analyze how artists confront their preconceptions when learning a song that requires portraying a very different character from 
the performer's own identity. For singers, the artistic process involves internalizing the multifaceted layers of meaning in a text (often in a foreign language) and expressing that interpretation through music, with beautiful vocalism, artistry, and dramatic commitment—no small task. In the world of opera, there is also a need for performers to appear believable in their roles, and directors often cast accordingly. It is true that in opera there is a history of stretching this verisimilitude because of vocal ideals rather than physical ones (pants roles, older women singing the part of young girls), but as a general rule audience members' expectations are not confused by what they see on stage in opera.

Art song, by contrast, is completely different. Each song presents its own unique world for the performer to inhabit. It would be a boring recital indeed if the singer chose only music that represented his or her physical appearance. We are called on to sing in many different languages, from the perspective of opposite genders and cultures far removed from our own. To make each situation believable for the audience, we must be guided by the composer's musical interpretation of the text to create a dramatically committed and coherent performance. Given that singers do this on a regular basis, why should we hesitate to sing from the perspective of another's race? The answer to that question is of course bound up in our culture's history of racism and oppression, but we would like to propose that the accepted performance practice of art songs offers a real opportunity to heal some of those wounds.

In the survey many African American singers said (to paraphrase), "If I can sing from a nineteenth-century white German man's point of view, why can't a white person sing from a slave's point of view?" At the University of Michigan School of Music, Theatre, and Dance, we invited a small but diverse group of undergraduate students to do just that. Our group consisted of two white female singers, two white male singers, and one black male singer, who first answered a series of questions about their backgrounds and their opinions of and previous exposure to art songs and spirituals by African Americans. With the help of their studio teachers as well as a course regularly offered at our university on the song literature of African Americans, the students explored their chosen repertoire. Some of them had guidance from African American professors, and some did not. At the end of the term, we conducted focus groups with the students, asking them specific questions about their expectations, their artistic process, and their discoveries. When they spoke of their experiences singing these spirituals and art songs by African American composers, many of them remarked on the freedom they felt because they had finally been given permission to sing from this perspective:

I was glad to have the opportunity to perform this repertoire with permission, because I've only ever seen black singers perform it and I've always wanted to be able to. 
Some of my pieces you couldn't tell what the perspective was, but some you could. I learned to dive in with confidence and push hesitation out of the way because we take on different characters all the time.

The main idea is to get ideas or emotion across no matter what your race.

The question of how their outlook on racial dynamics was affected can begin to be answered by looking at some of the other comments from our focus group in which students talked of the insights they gained after learning and performing these pieces:

"Singing outside the box" breaks cultural barriers and makes it much easier to connect to others. Performing makes you learn way more than just reading about it; it makes the experience much stronger.

Everybody learns about the Harlem Renaissance, but doing it [performing songs by poets and composers from that era] was way more powerful.

You need to understand the struggle and some of African American history and know how each song relates to the struggle. Each story is told from a different perspective.

I gained the most insight when I did my first mock performance-after the music was learned and memorized—and I was making choices about how I was going to make people believe me. I thought that, since I'm African American, my connection would be automatic, but my insight came through real performance.

All these singers were struck by the strong emotional content of the pieces and the music's unique ability to convey the universality of experience. One singer astutely summed up the potential of this musical tool for social awareness: "As a soloist, you search for the music that you are; the experience [is] more lasting, a self-fulfillment. [You have to engage in] more self-exploration because you're the sole communicator." In other words, you are required to empathize, not just sympathize, to do your job as a performer, and in art songs, you don't have costume, lights, or makeup to help you convince the audience.

What do we need to do as educators to enable singers from all racial backgrounds to become more comfortable performing this repertoire? First of all, voice teachers of all races should work together to convey the message that all students have "permission" to perform this repertoire. Second, to guide students toward committed, informed performances, we need to familiarize ourselves with the body of song literature and its proper performance practice (see Dunn-Powell, 2005; Steinhaus-Jordan, 2005; and Plant, 2005, for repertoire resources as well as discussion of performance practice). Third, we need to assign these pieces to students as part of their regular diet of quality music that is good for their voices and their development as 
artists. Fourth, we can program these songs in our own recitals so that our students can experience a live example of how it's done. Finally, we should follow up by talking to students about their experiences of singing these songs, which is easy to do in one-on-one studio teaching.

We plan to expand this study by continuing to collect and analyze stories about the barriers to and the impact of performing music by African American composers. As part of this work we have begun visiting colleges and universities around the country to present a lecture-recital and master class that would enable students who have learned pieces to perform them and to reflect with us on the impact the experience has on them as performers and audience members. Initial reactions at both campuses and academic conferences have been overwhelmingly positive from faculty and students of all racial backgrounds.

Performing the recital repertoire of art songs and spirituals by African Americans can be a wonderfully useful way for singers to confront their own preconceptions around race and performance practice, important issues for future professionals who will be performing for an increasingly diverse audience. There is no better place to attempt this task than in our colleges and universities, where teachers can guide and students can explore, pushing beyond the boundaries of their cultural assumptions in a safe environment where discussion of difficult topics is part of the process of their education as artists and citizens of the world.

\section{References}

Dunn-Powell, R. "The African-American Spiritual: Preparation and Performance Considerations." NATS Journal of Singing, 2005, 61(5), 469-475.

Hamm, C. Yesterdays: Popular Song in America. New York: Norton, 1979.

Plant, L. "Singing African-American Spirituals: A Reflection on Racial Barriers in Classical Vocal Music." NATS Journal of Singing, 2005, 61(5), 451-468.

Southern, E. The Music of Black Americans: A History. New York: Norton, 1971.

Steinhaus-Jordan, B. "Black Spiritual Art Song: Interpretive Guidelines for Studio Teachers." NATS Journal of Singing, 2005, 61(5), 477-485.

CAROLINE HELTON is clinical assistant professor of music (voice) at the University of Michigan School of Music, Theatre, and Dance.

EMERY STEPHENS is a doctoral student in vocal performance at the University of Michigan School of Music, Theatre, and Dance. 